\section{HETERO-LATERAL ECTOPIA OF THE RIGHT KIDNEY}

BY

\section{R. CAMPBELL BEGG, M.C., M.Sc., M.D., F.R.C.S.Ed., F.A.C.S., F.R.A.C.S. \\ (Johannesburg, South Africa)}

(With Special Plate)

This abnormality is rare but is of clinical importance. The chief features are brought out in the following case.

\section{Case Record}

A young man of 31 , a keen athlete and in perfect health, had been rejected for life insurance five years previously because a trace of albumin had been found in his urine. Examination showed no albumin in the early morning urine and no casts or other pathological findings, microscopical or chemical, at other times. He was normal generally, but palpation of the abdomen was difficult. No kidney could be felt on either side. The blood pressure was $136 / 80$ and the blood urea $42 \mathrm{mg}$. per $100 \mathrm{c.cm}$., both figures high for his age. Urea concentration was 2.18 per cent. in $95 \mathrm{c.cm}$. of urine passed in the second hour; urea clearance with urea (Fowweather's test) 76.9 c.cm. per minute. Blood urea at the end of the second hour was $66 \mathrm{mg}$., again a rather high figure. Intravenous pyelography to exclude polycystic kidneys showed no kidney on the right side and two on the left. He was then examined by cystoscopy and retrograde pyelograms-frontal, lateral, and stereoscopic. These were the findings:

Examination.-Bladder normal; ureteric orifices normal; the right ureter $20 \mathrm{~cm}$. in length, the left $27 \mathrm{~cm}$. The left kidney was normal in size and location, and also in calix distribution and formation. It was incompletely rotated, the pelvis lying in front. The right kidney had passed over to the left side. It lay below and ventral to the left kidney, overlapping its lower third. The pelvis was anterior and small, and was divided immediately into three major calices. The lower calices were normal, the upper large. The papillae of the latter were, however, not flattened. Both kidneys were about equal in size and showed good and equal function in the excretion of per-abrodil. The whole mass extended from the eleventh rib to just above the iliac crest. The left ureter passed forward over the upper part of the lower kidney and then gradually backwards, reaching the bladder on its own side. The right ureter crossed the middle line at the leve of the last lumbar vertebra and entered the bladder at the normal place on the right side (see Plate). When the kidney mass was pressed upwards the relative position of the two pelves was altered, and this, together with the clear overlapping individual shadows, indicated only slight fusion or none between the two kidneys.

There was nothing in these findings to indicate the reason for the albumin, though possibly the postural or vascular conditions which may bring this about in orthostatic albuminuria were imitated by the lower or displaced kidney.

\section{Discussion}

Stewart and Lodge (1923-4) in 6,500 necropsies found fourteen horseshoe, sixteen solitary, and one hetero-lateral ectopic kidney. Morris in 15,908 necropsies found one case of the latter type. If it is permissible to apply these figures to general populations London would have about 14,000 people with horseshoe kidneys, 16,000 with only one, and 1,000 with hetero-lateral ectopia. Owing to the enhanced susceptibility of abnormal kidneys to disease, more of these groups are likely to apply for treatment than similar groups of the ordinary population. Now solitary kidneys may be detected by cystoscopy because of a distorted trigone and only one functioning ureteric

orifice or, if the kidney is double, two orifices on the same side. Horseshoe kidneys may cause embarrassment, but are at least recognized at operation. Hetero-lateral ectopic kidneys, on the other hand, are not readily diagnosed by either of these methods. The ureteric orifices are normal and the passage of ureteral catheters without radiographs does not help. The two kidneys, if not fused, are in close relation within the capsule of Gerota, and even if two ureters are found it may be considered that they belong to a simple double kidney. Unless the surgeon is aware of the condition the whole of the renal substance may be removed, and this has happened on more than one occasion. In no case, then, should pyelograms or radiographs of opaque catheters be omitted.

The cause of hetero-lateral ectopia, especially in the 15 per cent. of cases without fusion, is not clear, but the condition must have its origin when the embryo is little larger than a grain of rice-probably through persistence of the usually transitory direction of the ureteric bud in a dorso-medial direction, which would carry the kidney anlage towards the middle and ultimately to the opposite side. Acute lesions such as rupture place these patients in the greatest danger if pyelography be omitted. Those interested in the subject will be able to follow the literature by referring to recent articles by Carleton (1937) and Patch (1937).

REFERENCES

Carleton, A. (1937). J. Anat., Lond., 71, 292

Patch, F.S (1937) Brit J Urol 9 339

Stewart, M. J., and Lodge, S. D. (1923-4). Brit. J. Surg., 11, 27.

\title{
HYPEROSTOSIS FRONTALIS INTERNA
} (STEWART-MOREL'S SYNDROME)

BY

T. de LEHOCZKY, M.D.

Lecturer in Neurology, University of Budapest

AND

\section{A. ORBÁN, M.D. \\ (With Special Plate)}

During the past few years neurologists have shown an increasing interest in the syndrome often associated with the name of Morel, and each new publication has made some contribution to our knowledge of its aetiology or clinical features. Schiff and Trelles (1931) were inclined to attribute the disorder to trauma ; L. van Bogaert (1930) has brought forth evidence to associate the visual defects with compression of the optic nerve in the bony foramen. There is still, however, a good deal of uncertainty both as to its pathogenesis and to its status as a clinical disorder. At the 1935 Congress of Pathologists in Oslo, Henschen even expressed doubts as to the existence of the syndrome.

\section{Case Report}

Eleven years age the patient, a woman aged 72 , had been ill with a herpes zoster in the left ophthalmic area followed by persistent neuralgic pains. $X$-ray treatment produced a severe dermatitis and ulceration over thc head, which healed with extensive scarring. A year ago alcohol was injected into the lower branch of the left trigeminal nerve. Since that time she has been subjected to numerous forms of treatment -with vaccines, opium, physiotherapy and psychotherapywithout benefit. She had been getting stouter during the last ten to fifteen years, especially over the trunk. No polyuria or polydipsia was present. Sleep was "inverted," the patient being restless during the night and sleepy, tired, and dizzy 
during the day. Other symptoms included depression, anxiety, tearfulness, and apathy to her surroundings.

On examination she was seen to be small and obese, her weight being $83 \mathrm{~kg}$. (182 lb.). The obesity had gradually developed during the past ten to fifteen years in the abdomen, around the pelvis and trunk. The extremities were slender, with proximal adiposity. The distribution of hair was normal. The internal organs were healthy, and the blood pressure was $180 / 110$. The second aortic sound was accentuated. There was a somewhat sluggish reaction of the pupils to light, more especially the left, but the fundus was normal. There was impairment of all forms of sensation over the first division of the fifth nerve on the left side and tenderness over the supra-orbital and infra-orbital notches. The corneal reflex was brisker on the right. Occasional vasomotor changes were observed over the second and third divisions of the left trigeminal area. Other cranial nerves were normal. There was no muscular wasting, and tonus and reflexes were normal. The patient's mental attitude was characterized by a lack of confidence and by irritability. She was markedly egocentric, all her interests and her activities being claimed by her affliction. She strove to make people around her realize the seriousness of her complaint. Her disease dominated the whole of her thoughts. Concentration, attention, and memory were impaired; her general intellectual level was poor, but her critical faculties were good, though primitive. The alkaline reserve was 54 per cent. by volume, the serum calcium $11.2 \mathrm{mg}$. per $100 \mathrm{c.cm}$., and the urinary creatine $59.8 \mathrm{mg}$. per $100 \mathrm{c.cm}$.

Radiographic Examination.-A skiagram of the skull taken nine years ago shows a conspicuous thickening of the cranial bones, especially in the frontal area. The same appearance is seen in the pictures taken four years ago (Plate, Fig. 1). The thickening of the occipital bone is now somewhat less pronounced and there is a senile atrophy of the mandible. No abnormality can be detected in the vascular pattern, the sella turcica, the sphenoidal sinuses, and the petrous bone. A skiagram taken one year later shows a more pronounced thickening in the frontal bone above the sinus, with marked enostosis. The frontal portion of the falx cerebri is calcified. The same changes, but more pronounced, are seen in the skiagram taken in 1936 (Fig. 2). Here the sella turcica shows some degree of decalcification.

The above case report corresponds with the StewartMorel syndrome of hyperostosis frontalis interna in the following particulars:

1. The progressive, symmetrical, and diffuse thickening of the cranial bones, most marked in the frontal and less marked in the parietal regions. The anterior portion of the falx cerebri is calcified and there is enostosis on both sides of the frontal bone.

2. Obesity of the rhizomelic type, developing during the past eleven years.

3. Intractable headaches, especially localized in the left frontal region.

4. Inverted sleep rhythm.

5. Psychological disturbances: (a) impairment of memory and attention; $(b)$ depression, anxiety, and irritability; (c) personality changes-egocentricity, hypochondriacal trends.

On the other hand our patient gave no evidence of excess of appetite, epileptiform attacks, visual disturbance, or dysuria-symptoms which are occasionally present in this disorder. According to Carr (1936) convulsive manifestations have been observed in 35.3 per cent. of the cases on record.

\section{Comment}

This case is of interest for two reasons. In the first place repeated radiographic examination has shown slow progression of the bony changes. Secondly, the onset of the symptoms at the age of 61 , following a trigeminal herpes zoster, is noteworthy. In this connexion we recall van Bogaert's case, that of a woman aged 62 with bilateral optic atrophy associated with the progressive ossification of the frontal bone. The unilateral occurrence of trigeminal symptoms in our patient is most probably due to the asymmetrical extension of the frontal hyperostosis.

\section{Aetiology}

Most writers have attributed this disease to a disorder of the fat and calcium metabolism. It is a striking fact, however, that Schiff and Trelles alone have been able to demonstrate a hypercalcaemia. Carr recorded a periodic creatinuria in his patients; this also occurred in the present case.

The theory of disordered fat metabolism has been corroborated by Mortimer's (1936) experiments on rats. Mortimer gave the animals the ketogenic factor of the anterior lobe of the pituitary gland. The animals so treated not only became fat but also showed a marked sclerosis of the calvarium. This experiment is of importance, too, in that it localizes the causation of the disease to the anterior lobe of the hypophysis. Stewart (1928) also inclined to a dyspituitary hypothesis, while Morel (1930) found in four patients very pronounced histological changes in the nuclei around the third ventricle. On this basis he localizes the lesion generally to the tuberinfundibulum-hypophyseal system, particularly in the posterior lobe of the pituitary body. In association with this conception is Moore's (1935) finding of thyroid disorder in 4.4 per cent. of his cases, while Carr described menstrual disturbances in 76.4 per cent.

Can the syndrome in question be considered an independent disorder? Henschen (1936) denies it, since frontal hyperostosis without accompanying symptoms is to be observed in 50 per cent. of women above the age of 50. In his own words, "the so-called Stewart-Morel syndrome is merely imagination."

In the light of the work carried out by Moore (1935), Mortimer, and others one must suppose that Henschen observed abortive or incompletely developed cases. The early stage of the disorder is well illustrated by Somogyi and Bak's (1937) patient, in whom there was only an early degree of hyperostosis with all the other symptoms fully developed.

Our case, together with the data to be found in the literature, inclines us to the opinion of Schiff and Trelles, according to whom the picture is not at present sufficiently circumscribed to be called a specific disease. We must consider the term "syndrome" correct and justifiable from a clinical viewpoint.

\section{REFERENCES}

Bogaert, L. van (1930). J. belge Neurol., 30, 502 Carr, A. D. (1936). Arch. Neurol. Psychiat., Chicago, 35, 982. Henschen, F. (1936). Acta path. microbiol., scand., Suppl., 28, 95. Moore, S. (1935). Surg. Gynec. Obstet., 61, 345. (1936). Amer. J. Roentgen., 35, 30.

Morel (1930). L'Hyperostose Frontale Interne, Paris.

Mortimer (1936). Arch. Neurol. Psychiat., Chicago, 35, 986.

Schiff, P., and Trelles, J. O. (1931). Encéphale, 26, 768.

Somogyi, I., and Bak, R. (1937). Dtsch. Z. Nervenheilk., 143, 199.

Stewart, R. M. (1928). J. Neurol. Psychopath., 8, 321.

In fifty-eight large towns in Germany there was a 2.8 per cent. decline in the mortality from tuberculosis in 1937, the deaths from this cause being 6.9 per 10,000 inhabitants, as compared with 7.1 in 1936. On the other hand there was a rise in the mortality from tuberculosis in Berlin, the Silesian towns, and the harbour towns in 1937. 
R. CAMPBELL BEGG: HETERO-LATERAL ECTOPIA UF THE RIGHT KIDNEY

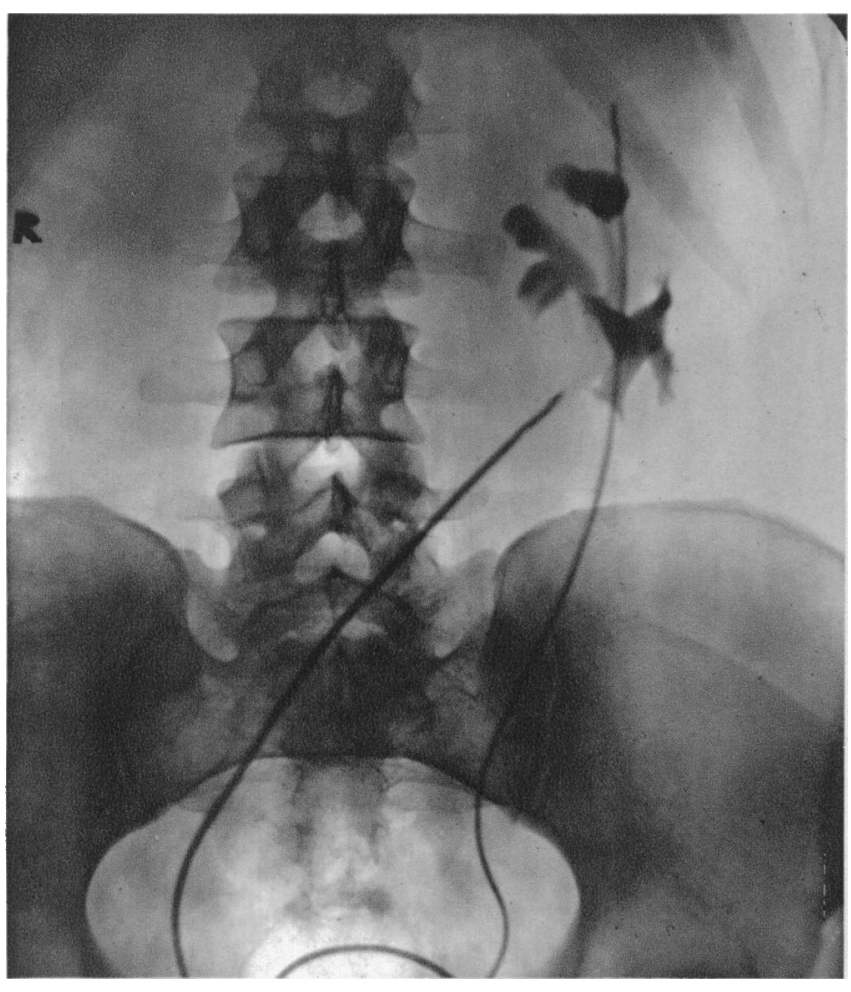

Fia. 1.-Pyelogram of the right or lower kidney. An opaque catheter lies in the left ureter, but the pelvis has not been injected.

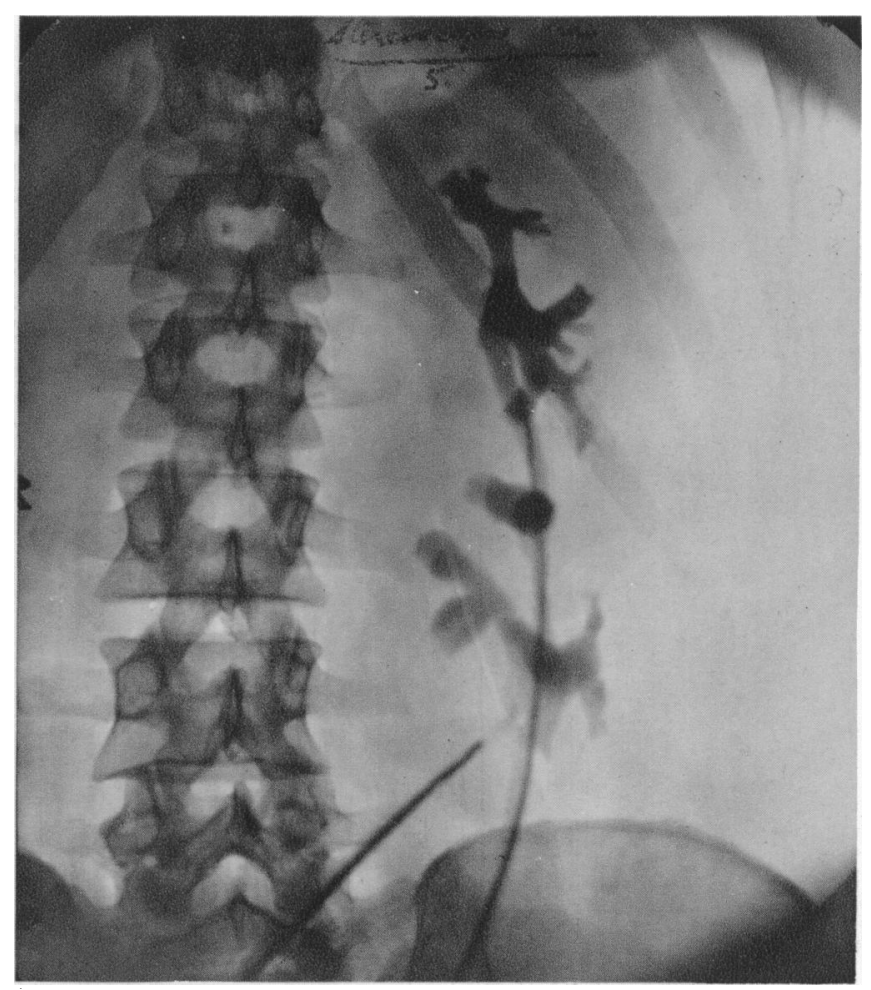

FiG. 2.-Retrograde pyelograms of both kidneys.

T. DE LEHOCZKY AND A. URBÁN : HYPEROSTOSIS FRONTALIS INTERNA 6

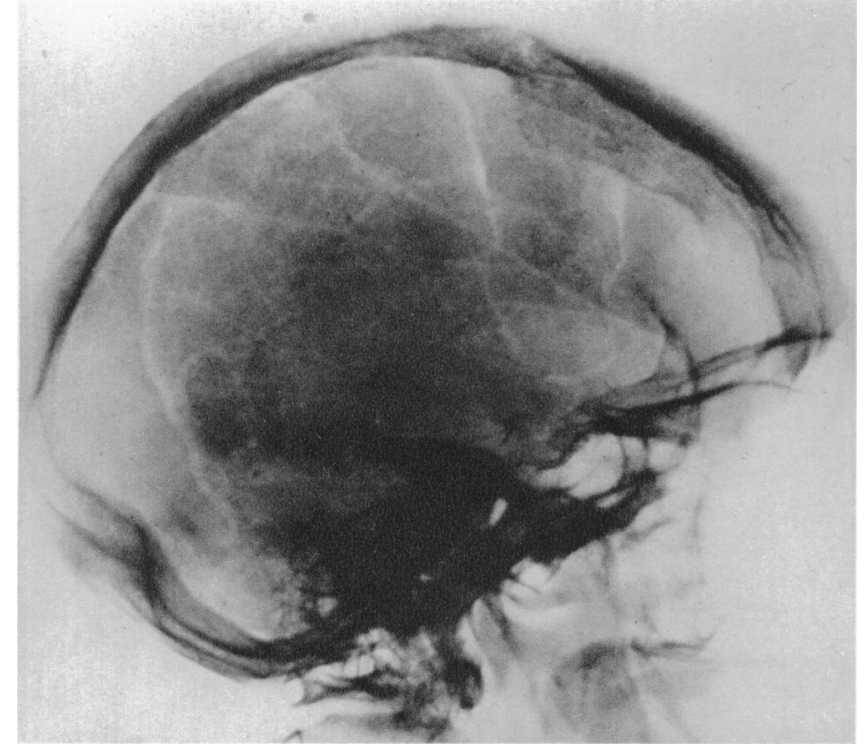

FIG. 1. - Skiagram of skull taken in 1934, showing conspicuous thickening of cranial bones, with senile atrophy of the mandible.

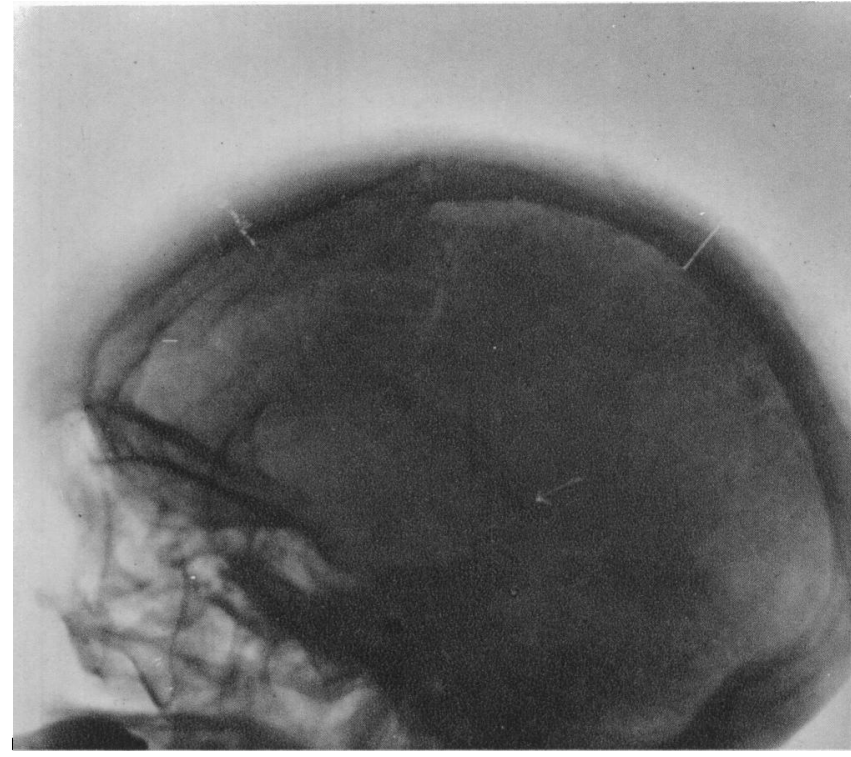

FiG. 2.-Skiagram taken in 1936. Same changes as in Fig. 1, but more pronounced, especially in the frontal bone above the sinus. The frontal portion of the falx cerebri is calcified. 